\title{
A Proposal of Indicators and Policy Framework for Innovation Benchmark in Europe
}

\author{
Juan Vicente García Manjón'
}

\begin{abstract}
The implementation of innovation policies has been adopted at European level from a common perspective. The European Council (2000) established open methods of coordination (OMC) in order to gain mutual understanding and achieving greater convergence on innovation policies, constituting a benchmarking procedure.

However, the development of benchmarking analysis for innovation policies faces two major inconveniences: the lack of accepted innovation policy frameworks and the existence of suitable indicators to measure their performance.

This article has a twofold objective: on the one hand, conducting an analysis of the existing innovation policy frameworks, putting forward a set of innovation policies which could be used as reference for policy analysis and on the other hand, proposing a set of indicators for measuring their performance.
\end{abstract}

Keywords: innovation policy; indicators; benchmarking; Europe.

\footnotetext{
' Facultad de Ciencias Jurídicas y Económicas. Universidad Europea Miguel de Cervantes. Calle Padre Julio Chevalier, $\mathrm{n}^{\circ} 2 . \mathrm{Valladolid.}^{\circ}$ (470 I2). España. Tel: 34. 983. 001000 Ext 229. E-mail: jvgarciam@uemc.es
} 


\section{Introduction}

The promotion of innovation is a major concern at regional, national and supranational level, since there is a wide consensus about the benefits of innovation on social an economic progress.

The implementation of innovation policies has been adopted at European level from a common perspective, based on common legal bases, policy plans and structures; deploying an array of innovation policies at different layers. Despite the existence of common goals and objectives, the implementation of innovation policies is not exempt from the necessity of encouraging the coordination mechanism, which constitutes a good departure point for policymakers.

Being aware of the above mentioned, the European Council (2000) established open methods of coordination (OMC) in order to gain mutual understanding and achieving greater convergence on innovation policies. The OMC were constituted following what could be identified as a benchmarking procedure.

However, the development of benchmarking analysis for innovation policies faces two major inconveniences: the lack of accepted innovation policy frameworks and the existence of suitable indicators to measure their performance.

This article has a twofold objective: on the one hand, conducting an analysis of the existing innovation policy frameworks, putting forward a set of innovation policies which could be used as reference for policy analysis and on the other hand, proposing a set of indicators for measuring the performance of innovation policies.

To conduct the work, the article is organised as follows: succeeding this introduction, the theoretical background of benchmarking of innovation policies is provided in section 2; a literature review about innovation systems and the definition of innovation policies is presented in section 3; a proposal of a set of indicators to measure innovation policies is presented in section 4; ending our work in section 5, where we include conclusions, limitations and future lines of research.

\section{Benchmarking of Innovation Policies}

The efforts at European level on innovation policies come from different ways, since regional innovation plans coexist with national and European strategies, which constitute a multilevel approach to the promotion of R\&D and innovation in Europe. However, it is necessary to assume that the position of EU Member States and regions differs significantly in their institutional infrastructure and economic conditions for innovations, being major differences expressed in terms of patterns of technological specialisation, intensity of R\&D investment, design of national and regional innovation systems, structure of business expenditure on innovation, degree of openness of national innovation systems (Balaz, Kluvankova, Zajac, 2005)

The EU is making a great effort in developing and coordinating innovation policies, adopting a joint innovation framework based on common legal bases (Art. 157 and 163-173 of EU Treaty), policy plans (Lisbon Strategy), programmes of action (R\&D Framework Programmes), and networks, all conforming the European Research Area (ERA).

Being aware of the necessity of policy coordination, the EU adopted, in the Lisbon Summit (European Council 2000, p. 37 ), the open method of coordination (OMC) in seven policy areas, including innovation, where have been established a number of soft governance instruments, clearly designed to achieve greater convergence of innovation policies at different territorial levels (Kaiser and Prange, 2004). The OMC was defined as the mean of spreading best practice and achieving greater convergence towards the main EU goals, being this definition quite closed to the benchmarking process. Accordingly, Lundvall and Tomlinson (2002) assert that the European Union adopted the benchmarking ideology for the public sector

The application of benchmarking to the public sector has different approaches, where authors like Groenendijk (2004) distinguishes between three types: benchmarking of public sector organisations, benchmarking of public policies and policy outcomes and finally benchmarking of policy systems.

Highlighting the final recommendations established in the Lisbon Summit, where it is identified the objectives and different steps of a benchmarking process; the declaration set the objectives of spreading best practice and achieving greater convergence towards the main EU goals, and invites to pursue the following procedures (European Council, 2000, p. 37): 
- Fixing guidelines for the Union combined with specific timetables for achieving the goals which the Member States set in the short, medium and long terms.

- Establishing, where appropriate, quantitative and qualitative indicators and benchmarks against the best in the world and tailored to the needs of different Member States and sectors as a mean of comparing best practice.

- Translating these European guidelines into national and regional policies by setting specific targets and adopting measures, taking into account national and regional differences.

- Periodic monitoring, evaluation and peer review organised as mutual learning processes.

The main challenge here is that such systems involve a multitude of policy objectives and actors whereas benchmarking of policies ideally involves a single set of coherent policy objectives and a defined set of policy actors (Berger, 2005).

Being aware of the aforementioned and concerning the necessity of defining coherent innovation policy sets and bearing in mind that innovation policy benchmarking still suffers from a lack of qualitative indicators (Kaiser and Prange, 2004), it is worth assuming the necessity of developing both: innovation policy frameworks and indicators that could be used in benchmarking procedures.

\section{Innovation Systems and the Definition of Innovation Policies}

The innovation system can be defined as a network of actors and institutions that develop, diffuse and use innovations (Malerba, 2002). The innovation systems approach explains innovation patterns in terms of technology and knowledge flows mediated by institutions, being initially applied at national level (Lundvall, 1992), and following at a regional, industrial and technological ones (Cooke, UrangA, Etxetarria, 1997; Cooke, Schienstock, 2000).

Policy intervention under the systemic approach shares the vision of market failures, where it is supposed to find connection imperfections between participants, which impedes knowledge generation and transfer (Smith, 2000), implying that policymakers can promote collective learning by mean of public intervention and that the whole system can be institutionally coordinated (Rondé and Hussler, 2005).

There is a wide range of market failures, among which we can highlight: infrastructural failures; transition failures; lock-in or path dependency failures; hard and soft institutional failures; strong or network failures; and, capabilities' failure (Carlsson, Jacobsson, 1997; Edquist et al., 1998; Smith, 1999).

It is also interesting referring to the functional perspective, which emphasizes the importance on what the system does or how it works in comparison to how it is composed or structured (Bergek et al., 2005), where policymakers can outline recommendations aiming at improving system performance enhancing its functions or eliminating structures that block system functions (Bergek et al., 2005).

This literature also refers to the concept of activities which are developed within the system, conceptualizing this term as the factors that influence the development, diffusion and use of innovations (Edquist, 2005). In order to give a reference of activities encompassing the system, we refer to the work of Chaminade and Equist (2005), Edquist (2005), and Liu and White (200I) who propose the following list of innovation system activities: creating and changing organizations; provision of R\&D; provision of education and training; articulation of quality requirements from the demand side; formation of new products markets, incubating activities; financing innovation processes, provision of consultancy services; creation and change of institutions; networking; and, interactive learning.

However, scholars and policy-makers face the inconvenience of defining innovation policy frameworks which serves to the purpose of the implementation and analysis of innovation. At this point, we have to assume that is worth referring to the different experiences in that field, and citing the existing innovation policy frameworks.

At European level is necessary to gather lessons learned since the early nineties, when there were set up initiatives such as the RIS (Regional Innovation Strategy) and RITTS (Regional Innovation and Technology Transfer Strategies and Infrastructure), but also it is valuable citing the Innovating Regions in Europe (IRE) Network, which have developed common structures for the analysis and mutual 
learning in the field of innovation policies, including initiatives of benchmarking of innovation policies, regional profile databases or regional foresight. Besides those initiatives, the European Commission keeps making great efforts by the creation and deployment of R\&D and innovation policy repositories, such as Prolnno Europe and Era Watch, gaining practical experience by gathering and managing innovation policy databases at a regional and national level.

Specially interesting for the purpose of this paper is the innovation policy classification put forward jointly by Prolnno Europe and Era Watch, which distinguishes five different policy areas, among which we can find: governance and horizontal research and innovation policies, research and technologies, human resources, promote and sustain the creation and growth of innovative enterprises and markets \& innovation culture.

As a result from the abovementioned initiatives, there have been developed several projects which have been focused on the study of the evaluation of innovation policies. Thus, we have to refer to the results from EMERIPA project, encompassing ten different innovation policy areas: education and skills; R\&D; regional intelligence; technology transfer; intellectual property; innovation financing; company innovation; new company creation; innovation centres; incubators and technology parks; and, clusters and sectors (EMERIPA, 2006).

It is also interesting citing the results from the STRINNOP project, which also renders a proposal of regional policy framework on innovation, including seven policy areas: identification of regional competencies; creation of regional knowledge; stimulation of innovation activities; implementation of firms' innovation activities; focus on regional strength; internationalisation; and, marketing of the regional innovation profile (STRINNOP, 2003).
Out of the regional perspective, one of the most relevant proposals at European level is the implementation of the European Trend Chart of Innovation developed by Arundel and Hollanders (2005). These authors propose eight policy groups including: intellectual property rights; commercialization of public research; research and development programmes; collaboration in innovation policies; financing innovation policies; human resources for innovation; targeted technology support; and, general innovation policies (Arundel and Hollanders, 2005). Later, Hollanders and Cruysen (2008) revised this literature identifying various system sub-functions and putting forward three blocks of functions: enablers; firm activities; and, outputs: So, they shape the innovation system outline under an input - output approach. More specifically, enablers capture the main drivers of innovation that are external to the firm, containing two dimensions: human resources, and financial support.

The European Commission (2009), based on the studies of Hertog, Rubalcaba and Segers (2008), and Hollanders and Cruysen (2008), also renders a classification of policy actions in support of innovation, distinguishing, on one hand, between specific and horizontal support policies and, on the other, between activity, firm, sector and market level.

Being aware of the aforementioned experiences, we put forward an innovation policy framework, which will be used for the purpose of this work. The framework encompasses seven different policy areas, each of them made up by four innovation policies, which makes twenty eight different innovation policies. The proposed framework is detailed in Figure I.

A proposal for innovation policy framework

I. Research \& Innovation governance and strategic intelligence for policy-making.

I.I Development of long term vision, studies and strategies in the field of R\&D and Innovation policies

I.I Definition of regional targets priorities for public and private investments in R\&D and Innovation

I.3 Implementation of R\&D and innovation governance structures (including specific regulation)

I.4 Encouraging transnational cooperation in R\&D and innovation. 
2. Research \& innovation friendly environment, including regulatory framework, taxes and regional aid.

2.I Grants to public sector R\&D and Innovation Institutions

2.2 Grants supporting business R\&D and Innovation including aid for researchers

2.3 Increase access to sources of finance for R\&D and Innovation including tax incentives

2.4 Improving the regulatory environment, administrative simplification and public procurement

3. Technology and knowledge transfer to enterprises and development of innovation poles and clusters and cooperation between public research and industry

3.I Developing public private partnerships for R\&D and Innovation (Research Centres, Universities, Business)

3.2 Promoting centres \& networks of excellence, regional research driven clusters and innovation poles

3.3 Improving R\&D cooperation and technology transfer

3.4 Strengthen innovation intermediaries

4. Creation and growth of innovative enterprises

4.I Funding facilities for innovative enterprises and start-ups including leveraging private funding

4.2 Supporting the promotion of innovation skills and the recruitment (identification) of innovators

4.3 Specific monitoring and R\&D programmes aimed to innovative enterprises

4.4 Disseminating the importance of business innovation culture

5. Intellectual property.

5.I Improvement of Intellectual Property Right regimes

5.2 Supporting the Intellectual Property protection at public and private level

5.3 Commercialization and transfer of IPR

5.4 Promote the use of IPR for Start -ups

6. Regional infrastructures for research and innovation.

6.I Encouraging the R\&D and Innovation system.

6.2 Promotion of R\&D services for enterprises

6.3 Infrastructures for start -ups and innovative enterprises

6.4 Supporting infrastructures for R\&D and Innovation (ICT, training...)

7. Human resources in research and innovation.

7.I Enhancing the mobility of researchers both at national and international level

7.2 Developing suitable conditions to attract researchers

7.3 Raising young people's interest in science, research and innovation

7.4 Cooperation between University and Enterprise (teaching and research)

Table I. A proposal for innovation policy framework. Source: Own elaboration based on different authors. 


\section{Establishment of Indicators to Measure Innovation Policies}

Once we have put forward an innovation policy framework, the objective of this section is to propose suitable indicators for their measurement. Thus, each policy area is analysed taking into account a general overview of the policy, previous literature considerations and afterwards, suggesting an array of indicators for the measurement of the policy area.

\section{Research and Innovation Governance and Strategic Intelligence for Policymaking.}

The foreseen impact of strategic planning in innovation policies is the gain of efficiency of the whole innovation systems, actors or policies. Therefore, strategic planning has a mainstreaming effect, which is quite difficult to specify in terms of impact on targets, policies or systems. We propose for that end a set of qualitative indicators, able to show the experience and rate of development in that policy area and the effort done by the region in innovation strategic planning: Implementation of R\&D plan (number of years since it is implemented); Implementation of an innovation plan (number of years since it is implemented) and Participation in RIS, RITTS, IRE.

This policy area also encompasses transnational cooperation policies. Nowadays, transnational cooperation in the field of innovation plays a key role in improving the innovation system itself. The more the businesses cooperate with other entities within or outside Europe, the stronger and wider the innovation system is. To measure the development of this policy action we propose the following indicators (Source: Eurostat): Share of enterprises engaged in any type of innovation cooperation, within Europe; Share of enterprises engaged in any type of innovation co-operation, within United States and other countries; Share of enterprises that received funding from the European Union and Share of enterprises that received funding from the Framework Programme

\section{Research \& Innovation Friendly Environment, including Regulatory Framework, Taxes and Regional Aid.}

One of the main concerns about these policies is their efficiency in terms of impact and we have to say that there is little consensus about this point as it has been stated by authors like Hall (2002). The Arundel and Hollanders (2005) does not find any correlation between the variable "share of enterprises receiving public funds for innovation" and the output-application variables, which include variables related to employment.

On the other hand, there is a clear correlation between the share of enterprises receiving public funding and the business R\&D expenditure (\% of the GDP) at geographic and firm level, (Toivanen, Niininen, 1998; Busom, 2000; Walsten, 2000; Czarnitzki, Fier, 200I; Almus, Czarnitzki, 2003)

In order to measure the progress in that policy area, we proposed to use the following indicators: "Share of enterprises that received any public funding" (Source: CIS). The indicator shows a breakdown by source of funding making a distinction between the "share of enterprises that received funding from local or regional authorities" and the "share of enterprises that received funding from central government" (including central government agencies or ministries).

Technology and Knowledge Transfer to Enterprises and Development of Innovation Poles and Clusters and Cooperation between Public Research and Industry.

According to the scientific literature, the determinants of the R\&D cooperation have been widely studied and vary with the kind of cooperation, the goals and the partnership. Thus, cooperation aimed to process improvement is more likely to be done in cooperation with suppliers, whereas product innovation is implemented with clients, (Fritsch and Rolf, 200I). Other authors state that cooperation in R\&D is mostly associated with firms promoting radical innovations than incremental innovations (Thether, 2002).

Cooperation with a type of partner generally is more likely to be chosen if such type of partner is considered an important source of knowledge for the innovation process, while more basic knowledge sourced from universities and research institutes positively influences all types of cooperation (Belderbos et al. 2003). However, the key question whether collaborative innovation has the expected positive impact on firms' (innovation) performance has remained largely unexplored in both the industrial organization as well in the management literature.

Focusing on the determination of relevant indicators that might measure the cooperation process, we propose the 
following indicators (Source: CIS): Innovative SME cooperating with others (\% of SMEs). This indicator encompasses the following ones, which go further in the analysis of cooperation activities: innovative SME cooperating with consultants, commercial labs, or private R\&D institutes/ innovative SME cooperating with Universities or other higher education institutions / innovative SME cooperating with Government or public research institutes.

\section{Creation and Growth of Innovative Enterprises}

It is largely assumed that funding is one of the main barriers to establish a new business and it often appears in the start-up and expansion phase of a business. These financial problems are more likely to occur when the new business is an innovative start-up or a new innovative firm desires to develop a growth plan. Apart from the traditional sources of funding (own funds, loans and overdrafts and grants), private equity funds is an alternative mean of funding innovative enterprises.

The success of new innovative firms largely depends on the availability to access to suitable sources of funding. Innovation policies can promote the creation of new financial instruments from the more traditional to the more modern, such as private equity or other financial instruments. Furthermore, it seems that technology based companies or innovative firms demand venture capital as a way of funding. Some authors like Lerner and Shepherd (2005) stated the importance of venture capital in funding innovation.

According to the results of the report of the European Venture Capital Association (EVCA, 2006), firms financed by venture capital funds post an annual growth clearly over the market average. Besides, the growth for venture capital firms in terms of employment uses to be higher for the smallest and high technology based firms than in the others.

Nevertheless, how do we measure innovation policies aiming to encourage the importance of new financial instruments for innovation? We have to review the former works developed in this field and cite the outcomes from EMERIPA (2006), where they proposed a set of indicators for that field: Venture capital investment as \% of the GDP; Regional public budget (direct expenses) financing innovation activities and Public budget (direct expenses) financing R\&D activities.
We also find interesting the results from the MERIPA (2007) project, where the following indicators are put forward in order to measure the effect of that policy: Share of high-tech, ICT, bio-tech, nano tech venture capital investment; New capital raised as \% of the GDP and Share of early stage venture capital as $\%$ of the GDP.

The other item included in this policy area is the support for the promotion of innovation skills and the recruitment of innovators. Authors like Utterback (1996) studied the innovation skills in relation with the innovation and technology along the product life cycle. The author exerts that radically new products demand entrepreneurial skills coupled with high-level specialist in technology and marketing, with adaptative workforce.

Accordingly, the promotion of innovation skills in the population in order to encourage the desired innovation skills seems to be related to the scientific and technological profile of human resources in a territory and the workforce capability for adaptation and continuing learning. Therefore, the question of evaluating the performance and impact of this policy should be treated considering the aforementioned items, proposing the following indicators for this policy (Source: Eurostat): Students (ISCED 5-6) enrolled in science, mathematics and computing field - as \% of all students; Students (ISCED 5-6) enrolled in engineering, manufacturing and construction field - as \% of all students; Graduates (ISCED 5-6) in mathematics, science and technology per I 000 of population aged 20-29 and Participation in life-long learning per 100 population aged 25-64.

\section{Intellectual Property}

The protection of intellectual assets is a way to facilitate the investment in research and development and to ensure that the dissemination of the R\&D results is done being aware of the creator's rights.

The patent is shown as a clear output of the innovation process. The European Innovation Scoreboard uses the number of patent applications to the European Patent Office (EPO) as a suitable indicator for measuring the innovation output.

At a macro-economy level, it is supposed that the more patent filed the higher the level of innovation and economic development. Accordingly, the European Innovation Scoreboard assumes that the number of applications to the EPO is a good way to measure the 
innovation output and the results of the effort done in research and development.

We propose the following indicator for this policy area (Source: Eurostat): EPO patents applications per million populations

Further to this point, it is also interesting to analyse other indicators based on patent data. Thus, besides the indicator, Patent applications to the EPO, we suggest the following: High-tech patent applications to the EPO; ICT patent applications to the EPO and Biotechnology patent applications to the EPO.

\section{Regional Infrastructures for Research and Innovation}

The performance in terms of innovation directly depends on the existing infrastructures for that end. It is largely assumed that a good innovation system, including infrastructures influences positively on the innovation performance, although there are other many factors that should be considered.

The first consideration to propose indicators for this area is that the development of infrastructures directly depends on the budget allocated to this aim. Apart from the fact that some of the research infrastructures belong to the business sector, from the point of view of innovation policies, we will consider the public budget allocated to $R \& D$ to evaluate the performance in this area.

Hence, we will propose the following indicators as a general measure of the performance of the region in that policy area (Source: Eurostat): R\&D expenditure (GERD) as a percentage of the GDP / R\&D expenditure (GERD) by the government sector as a percentage of the GDP and $R \& D$ expenditure (GERD) by the higher education sector as a percentage of the GDP

Besides the general overview provided by the set of indicators proposed, there need to find suitable indicators to measure policies 6.3 (Infrastructures for start-ups and innovative enterprises) and 6.4 (Supporting infrastructures for R\&D and innovation such as ICT).

The infrastructures for start-ups can vary from business incubators, business innovation centres to science or technological parks. If we want to measure the performance of this policy there are available indicators such as (Source: National Business Incubation Association): Number of Business Incubators per 10,000 Business Establishment
Following with this policy area, we will analyse the information and communication technologies support, looking for suitable indicators to measure this item. We propose a set of indicators to measure the development of this policy. On the one hand to measure the effort done to promote ICT and on the other hand the attainment level reached by individuals in the use of ICT (Source: Eurostat): Information technology expenditure as a percentage of the GDP / Broadband penetration rate.

\section{Human Resources in Research and Innovation}

Nowadays, the economic growth is led by the use of human capital. Knowledge economies are characterised by high productivity rates and the necessity to use high skilled workforce, which constitutes an essential input to the innovation system. Research and development play also a key role in the development of the virtuous circle of the knowledge base economies. Educated citizens play their role as users and as producers in a knowledge-based society, since the more innovative an economy is, the higher skills are required by individuals to become beneficiaries of this new product and services.

To analyse this policy we have to use a double approach. On the one hand, the stock of researchers in the innovation system clearly is an input policy that will influence on innovation output. On the other hand, the percentage of human resources working in knowledgebased sectors is an output or result of the R\&D and innovation policy.

There are many indicators, which can be used to evaluate the policy performance. We propose the following (Source: Eurostat): R\&D personnel in all sectors (\% of total employment) and the breakdown in; R\&D personnel in Business enterprise sector (\% of total employment); R\&D personnel in Government sector (\% of total employment); R\&D personnel in Higher education sector (\% of total employment) and R\&D personnel in Private non-profit sector (\% of total employment)

Another way to analyse the stock of human resources with the ability to generate knowledge is to study the human resources in science and technology (HRST). Following the Canberra Mannual, (OECD, 1995), the HRST are defined as the "number of persons who have successfully completed education at the third level in an S\&T field of study and who are employed in an S\&T occupation". The indicator is available from Eurostat: Human resources in science and technology (HRST) over the total population. 
It is also interesting to note that stocks of human resources aimed to science and technology constitute the actual resources for research and innovation. However, a prospective analysis about the future needs of human resources in that field drive us to investigate other items such as the young people's interest in science and technology. Thus, we look for indicators that could measure the likelihood that young people finally get involved in the science and innovation system.

Taking into account the above mentioned arguments we propose the following indicator (Source: Eurostat): Share of students following second stage of tertiary education leading to an advanced research qualification - level 6 (ISCED 1997) over total population.

To conclude this point, we present the analysis of human resources and employment from the output point of view. The share of employment in medium-high and high technology manufacturing sectors is an indicator of the knowledge economy that is based on continuing innovation through creative, inventive activity and it is considered as high tech industry. At the same time, the intensity of knowledge is applied at services, where the intensive use of this factor characterise this sectors as knowledgeintensive services. We propose two indicators to cover this topic (Source: Eurostat): Employment in medium-high and high-tech manufacturing (\% of total workforce) and Employment in high-tech services (\% of total workforce)

\section{Conclusions}

Since the European Council (2000) the benchmarking of innovation policies seems to be a way of policy coordination and the mean of achieving greater convergence in policymaking at different policy levels.

In order to implement the benchmarking process of innovation policies, it is necessary to count on a definition of a policy framework and the design of suitable indicators to measure their development and progress.

The definition of innovation policy frameworks has to bear in mind the concept of innovation systems, which constitutes the rationale for the categorization of innovation policies. At European level, there are a number of key references for innovation policy framing, being the European Trend Chart of Innovation one of the best examples of benchmarking on innovation policies.
The experience gathered from RIS, RITTS, IRE network, Proinno Europe and ERA Watch also constitutes a good reference point for defining a set of coherent innovation policies.

Thus, being aware of the above mentioned, we put forward a proposal encompassing seven policy areas: Research \& Innovation governance and strategic intelligence for policy-making; Research \& innovation friendly environment, including regulatory framework, taxes and regional aid; Technology and knowledge transfer to enterprises and development of innovation poles and clusters and cooperation between public research and industry; Creation and growth of innovative enterprises; Intellectual property; Regional infrastructures for research and innovation; Human resources in research and innovation.

On the other hand, our work proposes a set of indicators which can be used to measure the policy performance for each area, constituting a good reference point for innovation policy benchmark. Besides, the major part of the proposed indicators comes from official sources such as Eurostat, Community Innovation Survey, EPO...which facilitates the updating and data comparison.

However, there are several points that remain unexplored and make up a reference for future research works. According to this, we can refer to the necessity of making differences among the different layers (regional, national European) for the definition of innovation policy frameworks and going one step forward on the definition of suitable indicators which serve not only to measure the performance of one specific policy but the impact or effects of this policy at economic or social level.

\section{References}

ALMUS, M., Czarnitski, D. (2003). The effects of public R\&D subsidies on firms' innovation activities: The case of Eastern Germany. Journal of Business and Economic Statistics, $21(2)$, pp. 226-236.

ARUNDEL, A., Hollanders, H. (2005). Policy, Indicators and Targets: Measuring the Impacts of Innovation Policies, European Trend Chart of Innovation. MERIT. Maastricht. 
BALAZ, V., Kluvankova, T., Zajac, S. (2005). Conceptual economic issues of regional innovations. Institute for Forecasting, Slovak Academy of Science.

BELDERBOS, R., Carree, M., Diederen, B., Lokshin, B. and Veugelers, R. (2003). Heterogeneity in R\&D cooperation strategies. CEPR Discussion paper DP402 I. CEPR, London.

BERGEK, A., Jacobsson, S., Carlsson, B., Lindmarki, S., Rickne, A. (2005). Analysing the dynamics and functionality of sectoral innovation systems - a manual. 10 Year Anniversary DRUID Summer Conference, June 27-29, Copenhagen.

BERGER, G. (2005). Benchmarking for Innovation PolicyMaking - A Literature Review. ICCR

BUSOM, I. (2000). An empirical evaluation of the effects of R\&D subsidies. Economic Innovation and New Technology, 9, PP. III-I 48 .

CARLSSON, B., Jacobsson, S. (1997). In search of useful public policies: key lessons and issues for policy makers, in Carlsson (ed.), Technological Systems and Industrial Dynamics. Kluwer Academic Publishers, Dordrecht

CHAMINADE, C., Edquist, C. (2005). From Theory to Practice: The Use of Systems of Innovation Approach in Innovation Policy. Lund University, Lund.

COOKE, P., Schienstock, G. (2000). Structural competitiveness and learning regions. Enterprise and Innovation Management Studies, I(3), Pp. 265-280.

COOKE, P., Uranga, M.G., Etxebarria, G. (1997). Regional innovation systems: institutional and organizational dimensions, Research Policy, 26, pp. 475-49I.

CZARNITZKI, D., Fier, A. (200I). Do R\&D Subsidies Matter? - Evidence from the German Service Sector, ZEW Discussion Paper No. 0I-19. ZEW, Mannheim.

EDQUIST, C. (2005). Systems of innovation: perspectives and challenges. In: Fagerberg, Mowery and Nelson (eds.), The Oxford Handbook of Innovation, Pp. 18I-208. Oxford University Press, New York.
Statement - the Innovation Policy Implications of the 'Innovations Systems and European Integration', Research project. TSER programme (DG XII). Linkoping University.

EMERIPA (2006). Methodology for regional innovation strategy impact assessment and benchmarking. Aristotle University of Thessaloniki - Urban and Regional Innovation research unit (URENIO).

EUROPEAN COMMISSION (2009). Making public support for innovation in the $E U$ more effective: Lessons learned from a public consultation for action at Community level. Commission Staff Working Document. SEC(2009) I I 97 of 09.09.2009. European Communities. Brussels.

EVCA (2006). EVCA Yearbook 2006. EVCA, Belgium.

FRITSCH, M., Rolf, L. (200I). Who cooperates on R\&D? Research Policy, 30, pp. 297-312.

GROENENDIJK, N. S. (2004). The Use of Benchmarking in EU Economic and Social Policies, European Communities Studies Association (ECSA) annual meeting, University of Southern Denmark, 24-25 September 2004.

HALL, B.H. (2002). The financing of research and development. Oxford Review of Economic Policy 18(I), PP. $35-5$ I.

HERTOG, P. den, Rubalcaba L., Segers J. (2008). Is there a rationale for services $R \& D$ and innovation policies? International Journal of Services Technology and Management, 9(3-4), pp. 334-354.

HOLLANDERS, H., Cruysen, A. van (2008). Rethinking the European Innovation Scoreboard: A revised methodology for 2008-2010. Proinno Europe. European Commission.

KAISER, R., Prange, H. (2004). Managing Diversity in a System of Multi-Level Governance: The Open Method of Co-ordination in Innovation Policy, Journal of European Public Policy, I I (2), pp. 249-266.

LERNER, J., Moore D., Shepherd, S. (2005). A study of New Zealands venture capital and private equity market and implications for public policy. LECG Limited. Wellington.

EDQUIST, C., Hommen, L., Johnson, B., Lemola, T., Malerba, F., Reiss, T., Smith, K. (1998). The ISE Policy 
LIU, X., White, S. (200I). Comparing innovation systems: a framework and application to China's transitional context, Research Policy, 30(7), pp. I09I-III4.

EUROPEAN COUNCIL (2000). Lisbon European Council. Presidency Conclusions. European Council. Brussels.

LUNDVALL, B.A. (ed.) (1992). National Systems of Innovation: Towards a Theory of Innovation and Interactive Learning. Pinter, London.

LUNDVALL, B.A., Tomlinson, M. (2002). International Benchmarking as a Policy Learning Tool, in Rodrigues, M.J. (ed) The New Knowledge Economy in Europe: A strategy for International Competitiveness and Social Cohesion, Cheltenham: Edward Elgar, pp. 203-23I.

MALERBA, F. (2002). Sectoral systems of innovation and production, Research Policy, 3 I (2), pp. 247-264.

MERIPA (2007). Indicators and Benchmarking Tools Benchmarking Innovation Performance of Regions. EmiliaRomagna Region.

OECD (1995). Manual on the measurement of human resources devoted to S\&T "Canberra Manual". OECD, Paris.

RONDÉ, P., Hussler, C. (2005). Innovation in regions: what does really matter? Research Policy, 34, pp. II 50-I I 72.

SMITH, K. (1999). Innovation as a systemic phenomenon: rethinking the role of policy, in: Bryant and Wells (eds.), $A$ New Economic Paradigm? Innovation-Based Evolutionary Systems, PP. 10-47, Commonwealth of Australia, Department of Industry, Science and Resources, Science and Technology Policy Branch, Canberra.

SMITH, K. (2000). Innovation as a systemic phenomenon: rethinking the role of policy. Enterprise and Innovation Management Studies, I (I), pp. 73-102.

STRINNOP (2003). Guide book STRINNOP: How to Strengthen the regional innovation profile: A Pragmatic Approach. STRINNOP Project Consortium.

TETHER, B. (2002). Who co-operates for innovation, and why: an empirical analysis. Research Policy, 3I, pp. 947-967.
TOVAINEN, O., P. Niininen (2000). Investment, R\&D, subsidies, and credit constraints, Department of Economics MIT and Helsinki School of Economics, Working Papers no 244.

UTTERBACK, J. M. (1996). Mastering the Dynamics of Innovation, Harvard Business School Press, Boston MA.

WALLSTEN S.J. (2000). The effects of governmentindustry R\&D programs on private R\&D: The case of small business innovation research program, RAND Journal of Economics, 3I(I), pp. 82-100.

\section{About the Authors}

Juan Vicente García Manjón is PhD in Information Society and Telecommunications, Bachelor with honours in Business Administration, Master degree in Marketing and postgraduate studies in Technological Innovation, Management and Information technologies.

In 2005 I joined the European University Miguel de Cervantes (UEMC) as a full time lecturer in the field of business management. My field of research is innovation management and knowledge society.

Since 2008 I hold the position of Vicerrector of ESHE and Employment, managing the Bolonia process at the UEMC and implementing the quality and employment services.

I have also a wide experience in the private sector (technology and consultancy); I founded and run (CEO) Gateway Strategic Consultancy Services from 1998 to 2005. I also held the position of Vice-President at the Telecommunication Development Centre of Castilla León (CEDETEL). I've participated in the $\mathrm{VI}$ and VII R\&D Framework Programme as evaluator. 